\title{
Costs and readmission rates for the resection of primary and metastatic spinal tumors: a comparative analysis of 181 patients
}

\author{
Darryl Lau, MD, ${ }^{1}$ Andrew K. Chan, MD, ${ }^{1}$ Alexander A. Theologis, MD, ${ }^{2}$ Dean Chou, MD, ${ }^{1}$ \\ Praveen V. Mummaneni, MD, ${ }^{1}$ Shane Burch, MD, ${ }^{2}$ Sigurd Berven, MD, ${ }^{2}$ Vedat Deviren, MD, ${ }^{2}$ and \\ Christopher Ames, MD'
}

Departments of ${ }^{1}$ Neurological Surgery and ${ }^{2}$ Orthopaedic Surgery, University of California, San Francisco, California

\begin{abstract}
OBJECTIVE Because the surgical strategies for primary and metastatic spinal tumors are different, the respective associated costs and morbidities associated with those treatments likely vary. This study compares the direct costs and 90-day readmission rates between the resection of extradural metastatic and primary spinal tumors. The factors associated with cost and readmission are identified.
\end{abstract}

METHODS Adults (age 18 years or older) who underwent the resection of spinal tumors between 2008 and 2013 were included in the study. Patients with intradural tumors were excluded. The direct costs of index hospitalization and 90 -day readmission hospitalization were evaluated. The direct costs were compared between patients who were treated surgically for primary and metastatic spinal tumors. The independent factors associated with costs and readmissions were identified using multivariate analysis.

RESULTS A total of 181 patients with spinal tumors were included (63 primary and 118 metastatic tumors). Overall, the mean index hospital admission cost for the surgical management of spinal tumors was $\$ 52,083$. There was no significant difference in the cost of hospitalization between primary $(\$ 55,801)$ and metastatic $(\$ 50,098)$ tumors $(p=0.426)$. The independent factors associated with higher cost were male $\operatorname{sex}(p=0.032)$, preoperative inability to ambulate $(p=0.002)$, having more than 3 comorbidities $(p=0.037)$, undergoing corpectomy $(p=0.021)$, instrumentation greater than 7 levels $(p<0.001)$, combined anterior-posterior approach $(p<0.001)$, presence of a perioperative complication $(p<0.001)$, and longer hospital stay $(p<0.001)$. The perioperative complication rate was $21.0 \%$. Of this cohort, $11.6 \%$ of patients were readmitted within 90 days, and the mean hospitalization cost of that readmission was $\$ 20,078$. Readmission rates after surgical treatment for primary and metastatic tumors were similar (11.1\% vs $11.9 \%$, respectively) $(p=0.880)$. Prior hospital stay greater than 15 days (OR 6.62, $p=0.016$ ) and diagnosis of lung metastasis (OR 52.99, $p=0.007$ ) were independent predictors of readmission.

CONCLUSIONS Primary and metastatic spinal tumors are comparable with regard to the direct costs of the index surgical hospitalization and readmission rate within 90 days. The factors independently associated with costs are related to preoperative health status, type and complexity of surgery, and postoperative course.

http://thejns.org/doi/abs/10.3171/2016.2.SPINE15954

KEY WORDS cost; readmission; spinal tumor; tumor resection; oncology

$\mathrm{T}$ HE spine is a common location for the development of primary and metastatic tumors. Metastatic spinal tumors (secondary malignancies) make up the majority of all spinal tumors. In fact, $31 \%$ of autopsies of patients who die of a malignant neoplasm harbor sites of spinal metastases..$^{29}$ Most often, metastatic spinal tumors affect the bony vertebral column and are infrequently found in the intradural space. Conversely, primary spinal tumors may be benign or malignant, are relatively rare, and have a more heterogeneous origin as they may arise from the osseous spinal column, intradural extramedullary compartments, or spinal cord. Both primary and metastatic spinal lesions can demonstrate a range of benign and locally aggressive behaviors. 
The surgical indications, management, and goals of treating primary and metastatic tumors are different. Cure is the aim for primary tumors, while palliation to alleviate pain, restore or preserve neurological function, and stabilize the spine are the goals of metastatic tumor treatment. Therefore, surgical strategies are diverse and include simple decompression, local tumor debridement, complete tumor resection (via piecemeal or en bloc removal), and/ or spinal reconstruction, which may be accomplished via anterior and posterior approaches. ${ }^{19}$ Although the surgical treatment of metastatic and primary tumors of the spine may be associated with significant morbidity, surgery for metastatic tumors has been proven to offer significant improvements in Karnofsky Performance Scale scores and overall survival. ${ }^{23}$ Similarly, the outcomes of resection for primary spinal tumors are favorable. ${ }^{28}$

Improvement of functional outcomes is ideally accompanied by cost-effective care. Cost analyses of numerous spinal surgical techniques for treating various pathologies permeate the spine literature, ranging from the management of degenerative disc disease to scoliosis deformity. $1-3,7,10,11,16,21,24-27,30,31,38,39,43$ Elucidating the elements that affect the cost of spinal surgery can have significant implications for providing safe care in a cost-effective manner. There is a paucity of studies that directly evaluate the cost of surgery for spinal tumors. ${ }^{9,12,34,41,44}$ Many of the past studies have focused on the health care costs associated with managing (medically and/or surgically) heterogeneous cohorts of patients with bony metastasis ${ }^{8,13,14,17}$ or evaluated the cost effectiveness of adjuvant radiotherapy for spinal metastasis. ${ }^{15}$ In addition, among those studies there is a lack of details regarding the type of procedure performed or a dedicated analysis of the factors that affect cost. To the best of our knowledge, there are no studies comparing the costs between primary and metastatic spinal tumors. Therefore, in this study, we performed a detailed retrospective assessment of the index hospital costs associated with the surgical management of extradural primary and metastatic spinal tumors at a single institution. We compare the direct costs of primary and metastatic spinal tumors and identify the independent factors associated with cost. The independent risk factors for 90-day readmission are also examined.

\section{Methods}

\section{Patients}

The study cohort represents a consecutive series of adult patients (18 years or older) who underwent surgery for a spinal tumor between 2008 and 2013 at a single institution. The diagnosis of a spinal tumor was confirmed by histopathological analysis. Patients were excluded from the final analysis if they had an intradural tumor, underwent biopsy only, underwent kyphoplasty/vertebroplasty only, and/or did not have cost data available for analysis. The indications for surgery in the patients with either primary or metastatic spinal tumors were the presence of spinal cord or nerve compression with impending injury, presence of a neurological deficit, spinal instability due to bony destruction, growing radioresistant tumors, and/or intractable pain unresponsive to nonsurgical management.
In addition, for patients with metastatic tumors, patients were evaluated by the oncology team for advice regarding prognosis. Surgery was offered to patients with greater than 3 months of life expectancy.

\section{Data}

The primary outcome of interest was the direct cost associated with the index hospitalization. Cost data were obtained through the hospital's administrative records and represent the direct cost to the hospital for the patient's admission. These were based on 4 categories: surgical supplies (implants and other surgical supplies), services (including inpatient services such as physical/occupational therapy and intraoperative services such as operating room staffing fees, neuromonitoring, and fluoroscopy), room and care, and pharmacy services. Indirect costs (i.e., hospital administrative and facilities overhead, health information management, accounting and billing, and housekeeping) were excluded. Surgeon fees, the costs for a skilled nursing facility, and acute rehabilitation were not included in the direct cost data. Anesthesia fees were considered as a component of the operating room costs. The secondary outcomes of interest were the 90-day readmission rate and cost associated with hospitalization. The 90-day readmission rate concentrates only on the complications related to spinal tumor surgery.

The demographic data and clinical variables, including tumor type and perioperative outcomes, were retrospectively collected through detailed review of the medical records. The collected demographic and clinical variables included age (stratified as younger than 45 years, 45-65 years, and older than 65 years), sex, presence of preoperative neurological deficit, preoperative ability to ambulate, and presence of various comorbidities (psychiatric disease, thyroid disease, pulmonary disease, vascular disease, hyperlipidemia, diabetes mellitus, liver disease, kidney disease, stroke, and heart disease). The ability to ambulate was defined as upright walking with or without a walking aid, but without help from an individual. The use of preoperative, perioperative, and/or postoperative radiation therapy was recorded. The postoperative radiotherapies of interest were treatments administered within the 90-day readmission period. The tumor characteristics of interest included tumor type (primary or metastasis) and spinal region (cervical, thoracic, lumbar, or sacral). Data regarding extraspinal tumor burden and metastasis were recorded and categorized by the number of metastasis sites: $0,1,2$, and 3 or more. Perioperative parameters included type of procedure (corpectomy), number of levels instrumented, presence of perioperative complications, and length of hospitalization (in days). A perioperative complication was defined as any unforeseen event requiring additional medical or surgical care within the perioperative period.

\section{Statistical Analysis}

Descriptive statistical methods were used to define the mean direct cost and 90-day readmission rate. Bivariate analyses were used to test the associations of the covariates with the direct costs and readmission rates. Analysis of variance was used for continuous outcome variables 
(direct cost), and chi-square analysis was used for categorical outcomes (readmission rate). To identify independent factors associated with the outcomes of interest, multivariate analytical methods were employed. Multivariate analysis of covariance was used for continuous outcomes (direct cost), and logistic regression analysis was used for categorical outcomes (readmission rate). Covariates with a $\mathrm{p}$ value $<0.20$ were included in the final multivariate models. The threshold for statistical significance for this study was a $\mathrm{p}$ value less than 0.05 . All statistical analyses were performed using SAS (version 9.3 SAS Institute).

\section{Results}

Of the 222 patients initially identified, 181 patients met the a priori inclusion criteria and had sufficient data for the final analysis. The mean age was 55.0 years, and $52.5 \%$ of patients were male. Of the 181 patients, 63 patients (34.8\%) had primary spinal tumors and 118 patients $(65.2 \%)$ had metastatic spinal tumors. The types of primary tumors encountered in this cohort were chordomas, chondrosarcomas, giant cell tumors, nerve sheath tumors, schwannomas, neurofibromas, and hemangiomas. In patients with metastatic tumors, the tumor types encountered were testicular cancer, lung cancer, endometrial cancer, prostate cancer, breast cancer, renal cell carcinoma, cervical cancer, colon cancer, squamous cell carcinoma from the skin, melanoma, transitional cell bladder cancer, multiple myeloma, lymphoma, leiomyosarcoma, cholangiocarcinoma, and pancreatic adenocarcinoma. The tumors were most commonly located in the thoracic spine ( $47.0 \%$ of cases), and $35.9 \%$ of patients had extraspinal sites of metastasis. With regard to function, preoperative neurological deficits were present in $56.9 \%$ of patients, and $81.2 \%$ were able to ambulate. Of 181 patients, $67.4 \%$ underwent corpectomy and $70.1 \%$ underwent instrumented fusion. The perioperative complication rate was $21.0 \%$.

The overall mean index hospital cost for the surgical management of spinal tumors was $\$ 52,083$ (Table 1). There were no significant differences in the costs between patients who underwent surgery for a primary or metastatic spinal tumor ( $\$ 55,801$ vs $\$ 50,098$, respectively; $p=0.426$ ). Of the 181 patients, $40(22.1 \%)$ patients underwent radiation therapy: 32 preoperatively, 5 intraoperatively, and 3 postoperatively. The hospital costs were similar between patients who underwent radiotherapy and patients without radiation exposure $(\$ 52,200$ vs $\$ 51,671 ; \mathrm{p}=0.949)$. There were no significant differences in the direct hospital costs among patients, regardless of the presence or number of extraspinal metastasis. As shown in Table 1, the factors significantly associated with higher costs in the univariate analysis were the inability to ambulate $(\mathrm{p}=0.027)$, presence of vascular disease $(\mathrm{p}=0.037)$, procedures requiring corpectomy ( $p<0.001)$, more extensive instrumentation $(\mathrm{p}<0.001)$, combined anterior-posterior approach $(\mathrm{p}<$ $0.001)$, presence of perioperative complication ( $\mathrm{p}<0.001)$, and longer length of stay $(\mathrm{p}<0.001)$.

Table 2 shows the result of the multivariate analysis of the factors associated with the cost of surgical management for spinal tumors. Tumor type was not an independent factor associated with hospital cost $(\mathrm{p}=0.268)$.
TABLE 1. Covariates associated with the direct hospital cost of patients who underwent surgery for spinal tumors

\begin{tabular}{|c|c|c|c|}
\hline Variable & $\begin{array}{c}\text { No. of } \\
\text { Patients (\%) }\end{array}$ & $\begin{array}{l}\text { Mean Direct Cost } \\
\text { (SD) }\end{array}$ & $\begin{array}{c}p \\
\text { Value }\end{array}$ \\
\hline Total & 181 & $\$ 52,083(\$ 45,585)$ & NA \\
\hline Tumor type & & & 0.426 \\
\hline Primary tumor & $63(34.8)$ & $\$ 55,801(\$ 65,961)$ & \\
\hline Met & $118(65.2)$ & $\$ 50,098(\$ 29,961)$ & \\
\hline Diagnosis & & & 0.908 \\
\hline Chordoma & $23(12.7)$ & $\$ 65,413(\$ 56,633)$ & \\
\hline Chondrosarcoma & $10(5.5)$ & $\$ 59,113(\$ 31,581)$ & \\
\hline $\begin{array}{l}\text { Meningioma/nerve } \\
\text { sheath tumor }\end{array}$ & $31(17.1)$ & $\$ 48,775(\$ 79,115)$ & \\
\hline Prostate met & $13(7.2)$ & $\$ 48,503(\$ 40,196)$ & \\
\hline Breast met & $20(11.1)$ & $\$ 48,371(\$ 33,384)$ & \\
\hline Lung met & $21(11.6)$ & $\$ 45,023(\$ 22,896)$ & \\
\hline Renal cell met & $14(7.7)$ & $\$ 56,777(\$ 32,534)$ & \\
\hline Gastrointestinal met & $15(8.3)$ & $\$ 50,425(\$ 19,106)$ & \\
\hline Testicular met & $5(2.8)$ & $\$ 65,401(\$ 53,159)$ & \\
\hline Leiomyosarcoma met & $5(2.8)$ & $\$ 63,614(\$ 30,842)$ & \\
\hline $\begin{array}{l}\text { Multiple myeloma/ } \\
\text { leukemia met }\end{array}$ & $6(3.3)$ & $\$ 47,353(\$ 23,838)$ & \\
\hline Melanoma met & $5(2.8)$ & $\$ 18,802(\$ 5,206)$ & \\
\hline Uterine/cervical met & $5(2.8)$ & $\$ 44,658(\$ 8,532)$ & \\
\hline Other & $8(4.4)$ & $\$ 59,776(\$ 28,798)$ & \\
\hline Age, yrs & & & 0.419 \\
\hline$<45$ & $39(21.5)$ & $\$ 54,132(\$ 72,107)$ & \\
\hline $45-65$ & $104(57.5)$ & $\$ 54,499(\$ 38,520)$ & \\
\hline$>65$ & $38(21.0)$ & $\$ 43,368(\$ 24,411)$ & \\
\hline Sex & & & 0.152 \\
\hline Male & $95(52.5)$ & $\$ 56,717(\$ 53,095)$ & \\
\hline Female & $86(47.5)$ & $\$ 46,965(\$ 35,451)$ & \\
\hline Neurological deficit & & & 0.409 \\
\hline Yes & $103(56.9)$ & $\$ 54,535(\$ 51,322)$ & \\
\hline No & $78(43.1)$ & $\$ 48,846(\$ 37,105)$ & \\
\hline Ambulatory & & & 0.027 \\
\hline Yes & $147(81.2)$ & $\$ 48,483(\$ 36,448)$ & \\
\hline No & $34(18.8)$ & $\$ 67,651(\$ 72,197)$ & \\
\hline Radiation therapy & & & 0.949 \\
\hline Yes & $40(22.1)$ & $\$ 52,200(\$ 49,094)$ & \\
\hline No & $141(77.9)$ & $\$ 51,671(\$ 31,491)$ & \\
\hline Extraspinal met & & & 0.724 \\
\hline 0 & $116(64.1)$ & $\$ 54,679(\$ 53,229)$ & \\
\hline 1 & 31 (17.1) & $\$ 49,433(\$ 27,419)$ & \\
\hline 2 & $18(9.9)$ & $\$ 48,794(\$ 30,542)$ & \\
\hline$\geq 3$ & $16(8.8)$ & $\$ 42,099(\$ 24,599)$ & \\
\hline \multicolumn{4}{|l|}{ Comorbidities } \\
\hline Psychiatric & & & 0.554 \\
\hline Yes & $26(14.4)$ & $\$ 47,152(\$ 30,467)$ & \\
\hline No & $155(85.6)$ & $\$ 52,911(\$ 47,821)$ & \\
\hline
\end{tabular}

CONTINUED ON PAGE $369 »$ 
» CONTINUED FROM PAGE 368

TABLE 1. Covariates associated with the direct hospital cost of patients who underwent surgery for spinal tumors

\begin{tabular}{|c|c|c|c|}
\hline Variable & $\begin{array}{c}\text { No. of } \\
\text { Patients (\%) }\end{array}$ & $\begin{array}{l}\text { Mean Direct Cost } \\
\text { (SD) }\end{array}$ & $\begin{array}{c}p \\
\text { Value }\end{array}$ \\
\hline \multicolumn{4}{|c|}{ Comorbidities (continued) } \\
\hline Thyroid disease & & & 0.517 \\
\hline Yes & $14(7.7)$ & $\$ 59,712(\$ 33,518)$ & \\
\hline No & $167(92.3)$ & $\$ 51,444(\$ 46,610)$ & \\
\hline Pulmonary & & & 0.301 \\
\hline Yes & $21(11.6)$ & $\$ 42,360(\$ 21,718)$ & \\
\hline No & $160(88.4)$ & $\$ 53,359(\$ 47,875)$ & \\
\hline Vascular & & & 0.037 \\
\hline Yes & $18(9.9)$ & $\$ 73,334(\$ 97,516)$ & \\
\hline No & $163(90.1)$ & $\$ 49,737(\$ 35,610)$ & \\
\hline Hyperlipidemia & & & 0.562 \\
\hline Yes & $22(12.2)$ & $\$ 50,612(\$ 33,922)$ & \\
\hline No & $159(87.8)$ & $\$ 52,287(\$ 47,193)$ & \\
\hline Diabetes mellitus & & & 0.326 \\
\hline Yes & $17(9.4)$ & $\$ 41,696(\$ 29,628)$ & \\
\hline No & $164(90.6)$ & $\$ 53,160(\$ 46,999)$ & \\
\hline Liver disease & & & 0.914 \\
\hline Yes & $10(5.5)$ & $\$ 53,603(\$ 39,764)$ & \\
\hline No & $171(94.5)$ & $\$ 51,994(\$ 46,137)$ & \\
\hline Kidney disease & & & 0.259 \\
\hline Yes & $10(5.5)$ & $\$ 67,982(\$ 41,292)$ & \\
\hline No & $171(94.5)$ & $\$ 51,154(\$ 45,896)$ & \\
\hline Stroke & & & 0.743 \\
\hline Yes & $2(1.1)$ & $\$ 41,484(\$ 41,484)$ & \\
\hline No & $179(98.9)$ & $\$ 52,202(\$ 45,892)$ & \\
\hline Hypertension & & & 0.843 \\
\hline Yes & $54(29.8)$ & $\$ 53,123(\$ 32,948)$ & \\
\hline No & $127(70.2)$ & $\$ 51,641(\$ 50,277)$ & \\
\hline Heart disease & & & 0.985 \\
\hline Yes & $19(10.5)$ & $\$ 51,893(\$ 35,649)$ & \\
\hline No & $162(89.5)$ & $\$ 52,106(\$ 46,840)$ & \\
\hline Total comorbidities & & & 0.058 \\
\hline None & 71 (39.2) & $\$ 50,670(\$ 42,541)$ & \\
\hline $1-3$ & $98(54.1)$ & $\$ 51,152(\$ 49,254)$ & \\
\hline$>3$ & $12(6.6)$ & $\$ 68,051(\$ 31,378)$ & \\
\hline Spinal region & & & 0.353 \\
\hline Cervical & $34(18.8)$ & $\$ 58,781(\$ 48,595)$ & \\
\hline Thoracic & $85(47.0)$ & $\$ 47,925(\$ 27,104)$ & \\
\hline Lumbar & $43(23.8)$ & $\$ 49,044(\$ 37,724)$ & \\
\hline Sacral & $19(10.5)$ & $\$ 65,581(\$ 97,141)$ & \\
\hline Corpectomy & & & $<0.001$ \\
\hline Yes & $122(67.4)$ & $\$ 63,484(\$ 50,086)$ & \\
\hline No & $59(32.6)$ & $\$ 28,509(\$ 20,311)$ & \\
\hline Fusion & & & $<0.001$ \\
\hline None & $54(29.8)$ & $\$ 22,753(\$ 13,277)$ & \\
\hline $1-7$ & $100(55.2)$ & $\$ 59,893(\$ 47,497)$ & \\
\hline$>7$ & $27(14.9)$ & $\$ 81,819(\$ 50,767)$ & \\
\hline
\end{tabular}

CONTINUED IN NEXT COLUMN »
" CONTINUED FROM PREVIOUS COLUMN

TABLE 1. Covariates associated with the direct hospital cost of patients who underwent surgery for spinal tumors

\begin{tabular}{lrcc}
\hline \multicolumn{1}{c}{ Variable } & $\begin{array}{c}\text { No. of } \\
\text { Patients }(\%)\end{array}$ & $\begin{array}{c}\text { Mean Direct Cost } \\
(\text { SD) }\end{array}$ & $\begin{array}{c}p \\
\text { Value }\end{array}$ \\
\hline $\begin{array}{c}\text { Anterior-posterior ap- } \\
\text { proach }\end{array}$ & & & $<0.001$ \\
\hline Yes & $49(27.1)$ & $\$ 82,214(\$ 64,887)$ & \\
\hline No & $132(72.9)$ & $\$ 40,898(\$ 29,372)$ & \\
\hline Complication & & & $<0.001$ \\
\hline Yes & $38(21.0)$ & $\$ 86,609(\$ 76,143)$ & \\
\hline No & $143(79.0)$ & $\$ 42,909(\$ 27,097)$ & \\
\hline Length of stay & & & $<0.001$ \\
\hline$<5$ & $36(19.9)$ & $\$ 21,904(\$ 12,474)$ & \\
\hline $5-10$ & $75(41.4)$ & $\$ 38,340(\$ 19,675)$ & \\
\hline $11-15$ & $40(22.1)$ & $\$ 62,478(\$ 23,151)$ & \\
\hline$>15$ & $30(16.6)$ & $\$ 108,798(\$ 77,315)$ & \\
\hline
\end{tabular}

Met $=$ metastasis $; \mathrm{NA}=$ not applicable.

Rather, several other clinical and perioperative variables were independently associated with hospital cost. The preoperative factors independently associated with direct cost can be seen in Table 2 and Fig. 1. Male sex was independently associated with higher cost compared with female sex ( $\$ 56,717$ vs $\$ 46,965$, respectively; $p=0.032)$ (Fig. 1A). The ability to ambulate preoperatively was an independent factor associated with cost $(\mathrm{p}=0.002)$; ambulatory patients had a significantly lower cost $(\$ 48,483)$ than nonambulatory patients $(\$ 67,651)$ (Fig. 1B). With regard to comorbidities, having more than 3 medical comorbidities was independently associated with higher cost $(p=0.037)$ : no comorbidities, $\$ 50,670 ; 1$ to 3 comorbidities, $\$ 51,152$; and more than 3 comorbidities, \$68,051 (Fig. 1C).

The surgical factors that were independently associated with cost can be seen in Table 2 and Fig. 2. Performing a corpectomy $(\mathrm{p}<0.001)$, undergoing instrumentation involving more than 7 levels (relative to no fusion) ( $\mathrm{p}<$ 0.001 ), and approaching the spine through a combined anterior-posterior approach $(\mathrm{p}<0.001)$ were all independently associated with higher cost. Patients who underwent corpectomy had a mean cost of $\$ 63,483$ compared with $\$ 28,509$ in patients who did not undergo corpectomy (Fig. 2A). Instrumentation of more than 7 levels had a mean cost of $\$ 81,818$; this was significantly higher than both instrumentation of 1 to 7 levels $(\$ 59,893)$ and no instrumentation (\$22,753) (Fig. 2B). A combined anteriorposterior approach was associated with a cost of $\$ 82,214$; this is approximately double the cost of a single approach $(\$ 40,898)$ (Fig. 2C).

The postoperative factors independently associated with hospital cost are shown in Table 2 and Fig. 3. Patients who experienced a complication had approximately double the cost of patients without complications $(\$ 86,609$ vs $\$ 42,909$, respectively; $p<0.001$ ) (Fig. 3 left). A length of stay greater than 5 days was independently associated with higher cost compared with 5 to 10 days $(\mathrm{p}=0.011), 11$ to 15 days $(\mathrm{p}=0.064)$, and longer than 15 days $(\mathrm{p}<0.001)$. 
TABLE 2. Results of the multivariate analysis of the factors that may influence the direct hospital cost in patients who undergo surgery for spinal tumors

\begin{tabular}{|c|c|c|}
\hline Factor & Mean Direct Cost (SD) & $p$ Value \\
\hline \multicolumn{3}{|l|}{ Tumor type } \\
\hline Primary tumor & $\$ 55,801(\$ 65,961)$ & Ref \\
\hline Met & $\$ 50,098(\$ 29,961)$ & 0.268 \\
\hline \multicolumn{3}{|l|}{ Sex } \\
\hline Male & $\$ 56,717(\$ 53,095)$ & 0.032 \\
\hline Female & $\$ 46,965(\$ 35,451)$ & Ref \\
\hline \multicolumn{3}{|l|}{ Ambulatory } \\
\hline Yes & $\$ 48,483(\$ 36,448)$ & Ref \\
\hline No & $\$ 67,651(\$ 72,197)$ & 0.002 \\
\hline \multicolumn{3}{|l|}{ Vascular disease } \\
\hline Yes & $\$ 73,334(\$ 97,516)$ & 0.194 \\
\hline No & $\$ 49,737(\$ 35,610)$ & Ref \\
\hline \multicolumn{3}{|l|}{ Total comorbidities } \\
\hline None & $\$ 50,670(\$ 42,541)$ & Ref \\
\hline $1-3$ & $\$ 51,152(\$ 49,254)$ & 0.205 \\
\hline$>3$ & $\$ 68,051(\$ 31,378)$ & 0.037 \\
\hline \multicolumn{3}{|l|}{ Corpectomy } \\
\hline Yes & $\$ 63,484(\$ 50,086)$ & 0.021 \\
\hline No & $\$ 28,509(\$ 20,311)$ & Ref \\
\hline \multicolumn{3}{|l|}{ Fusion } \\
\hline None & $\$ 22,753(\$ 13,277)$ & Ref \\
\hline $1-7$ & $\$ 59,893(\$ 47,497)$ & 0.024 \\
\hline$>7$ & $\$ 81,819(\$ 50,767)$ & $<0.001$ \\
\hline \multicolumn{3}{|c|}{ Anterior-posterior approach } \\
\hline Yes & $\$ 82,214(\$ 64,887)$ & $<0.001$ \\
\hline No & $\$ 40,898(\$ 29,372)$ & Ref \\
\hline \multicolumn{3}{|l|}{ Complication } \\
\hline Yes & $\$ 86,609(\$ 76,143)$ & $<0.001$ \\
\hline No & $\$ 42,909(\$ 27,097)$ & Ref \\
\hline \multicolumn{3}{|l|}{ Length of stay, days } \\
\hline$<5$ & $\$ 21,904(\$ 12,474)$ & Ref \\
\hline $5-10$ & $\$ 38,340(\$ 19,675)$ & 0.011 \\
\hline $11-15$ & $\$ 62,478(\$ 23,151)$ & 0.064 \\
\hline$>15$ & $\$ 108,798(\$ 77,315)$ & $<0.001$ \\
\hline
\end{tabular}

Ref $=$ reference .

The costs of each categorized length of stay were as follows: less than 5 days ( $\$ 21,904), 5$ to 10 days $(\$ 38,340), 11$ to 15 days $(\$ 62,478)$, and greater than 15 days $(\$ 108,798)$ (Fig. 3 right).

Overall, the 90-day readmission rate for the cohort was $11.6 \%$ (Table 3). The mean hospital cost for the 90-day readmission was $\$ 20,078$. There was no significant difference in the readmission rates between patients who had primary tumors $(11.1 \%)$ compared with patients who had metastatic tumors $(11.9 \%)(\mathrm{p}=0.880)$. Radiation therapy also was not significantly associated with the 90-day readmission rate: $15.0 \%$ of patients who underwent radiation treatment were readmitted, and $10.6 \%$ of readmitted patients did not undergo radiation therapy $(\mathrm{p}=0.447)$. The presence or number of extraspinal metastases was not significantly associated with the 90-day readmission rate. The only variable that was significantly associated with a higher readmission rate in the univariate analysis was the presence of vascular disease $(\mathrm{p}=0.024)$.

Table 4 shows the results of the multivariate analysis of the independent risk factors associated with 90-day readmission. Two factors were independently associated with readmission: diagnosis of lung metastasis (Table 4 and Fig. 4 upper) and index hospitalization length of stay (Table 4 and Fig. 4 lower). A diagnosis of lung metastasis was associated with an increase in the odds of 90-day readmission relative to a diagnosis of breast cancer (odds ratio 52.99; 95\% confidence interval 2.96-948.39; $\mathrm{p}=0.007$ ). Relative to a length of stay shorter than 5 days, patients who stayed in the hospital for longer than 15 days during the initial admission had 6.62 higher odds of being readmitted within 90 days (95\% confidence interval 1.30-33.74; $\mathrm{p}$ $=0.016)$. The readmission rates stratified by prior length of stay are as follows: shorter than 5 days (2.8\%), 5 to 10 days (12.0\%), 11 to 15 days (12.5\%), and longer than 15 days $(20.0 \%)$. The reasons for readmissions are included in Table 5.

\section{Discussion}

This study utilizes a single institutional cohort to review the direct cost of hospitalization for spinal tumor surgery. Overall, the mean cost of admission for surgery was $\$ 52,083$, and there were no differences in costs when operating on primary or metastatic spinal tumors. Rather, the findings of this study suggest that there are various preoperative, surgical, and postoperative factors that have the potential to influence and alter hospital cost. The 90day readmission rate in this cohort was $11.6 \%$, and there was no difference in this rate following the treatment of primary or metastatic spinal tumors. With further understanding of the factors associated with cost of surgery and readmission for spinal tumor surgery, improvements can be made to enhance future cost effectiveness.

There are only a few studies in the literature that have concentrated on the cost associated with the surgical management of spinal tumors. Among those articles, hospitalization costs range widely secondary to the variability in the procedures performed, pathologies treated, and geographic location (such as different countries). ${ }^{9} 12,34,41,44$ None of the available studies evaluate and compare the cost of both primary and metastatic spinal tumors. There are several articles that have examined the health care utilization and cost associated with the management of general bony metastasis and its associated "skeletal events," with some providing a subanalysis of spinal column metastasis. ${ }^{8,13,14,17}$ These studies contain a heterogeneous cohort of patients, but offer a valuable sense of the expense associated with the management of bony metastasis. The average cost of treating a skeletal event secondary to metastasis is reported to range from $\$ 10,000$ to $\$ 12,000 . .^{14,22}$ This seems to be a relatively low cost; however, the reported means include both medical and surgical management modalities (with surgery making up a very small proportion of cases). 

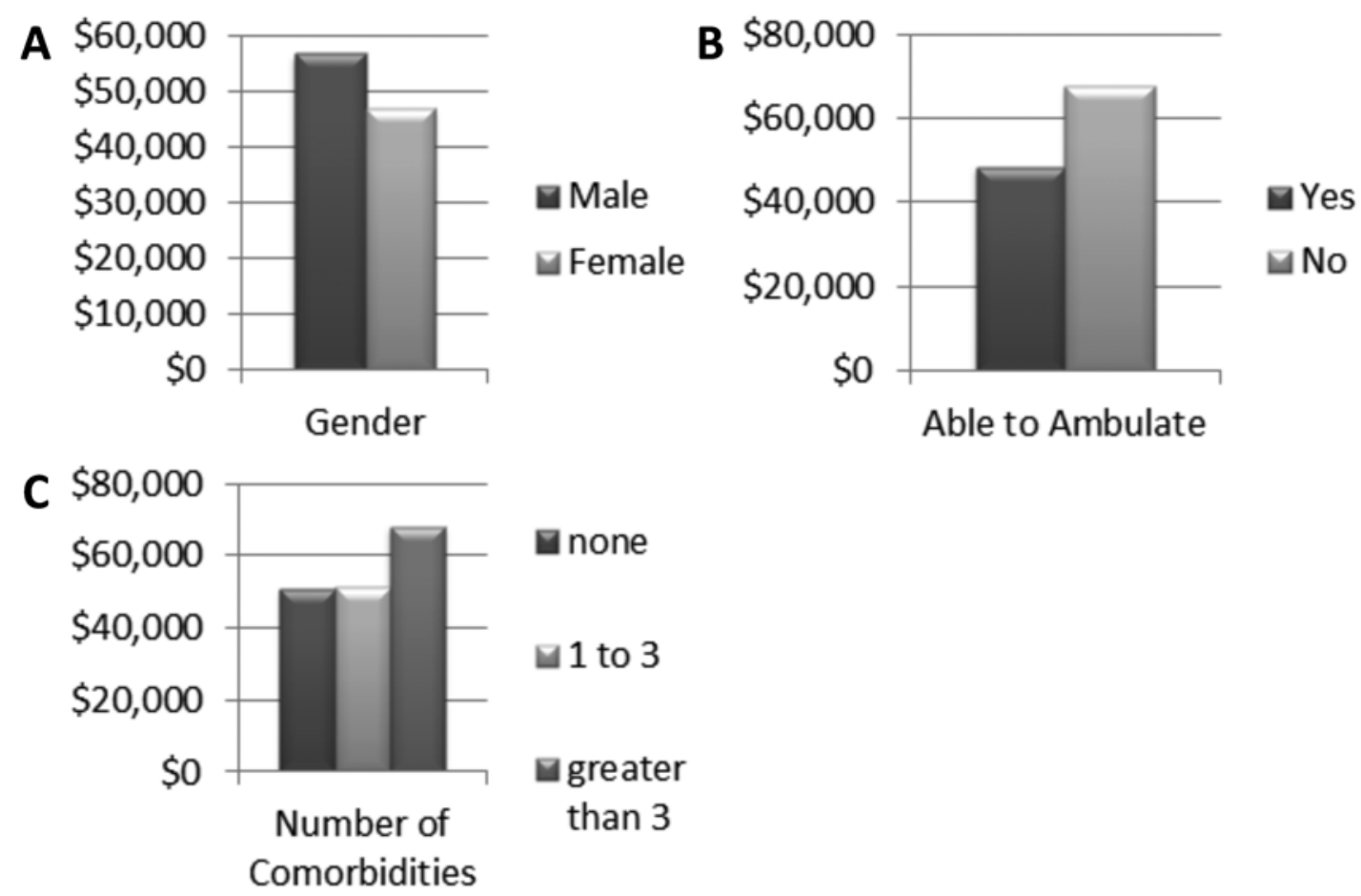

FIG. 1. Preoperative factors significantly associated with hospital cost in patients undergoing surgery for spinal tumors. Male sex $(p=0.032)(A)$, inability to ambulate $(p=0.002)(B)$, and having more than 3 comorbidities $(p=0.037)(C)$ were all independently associated with higher cost.
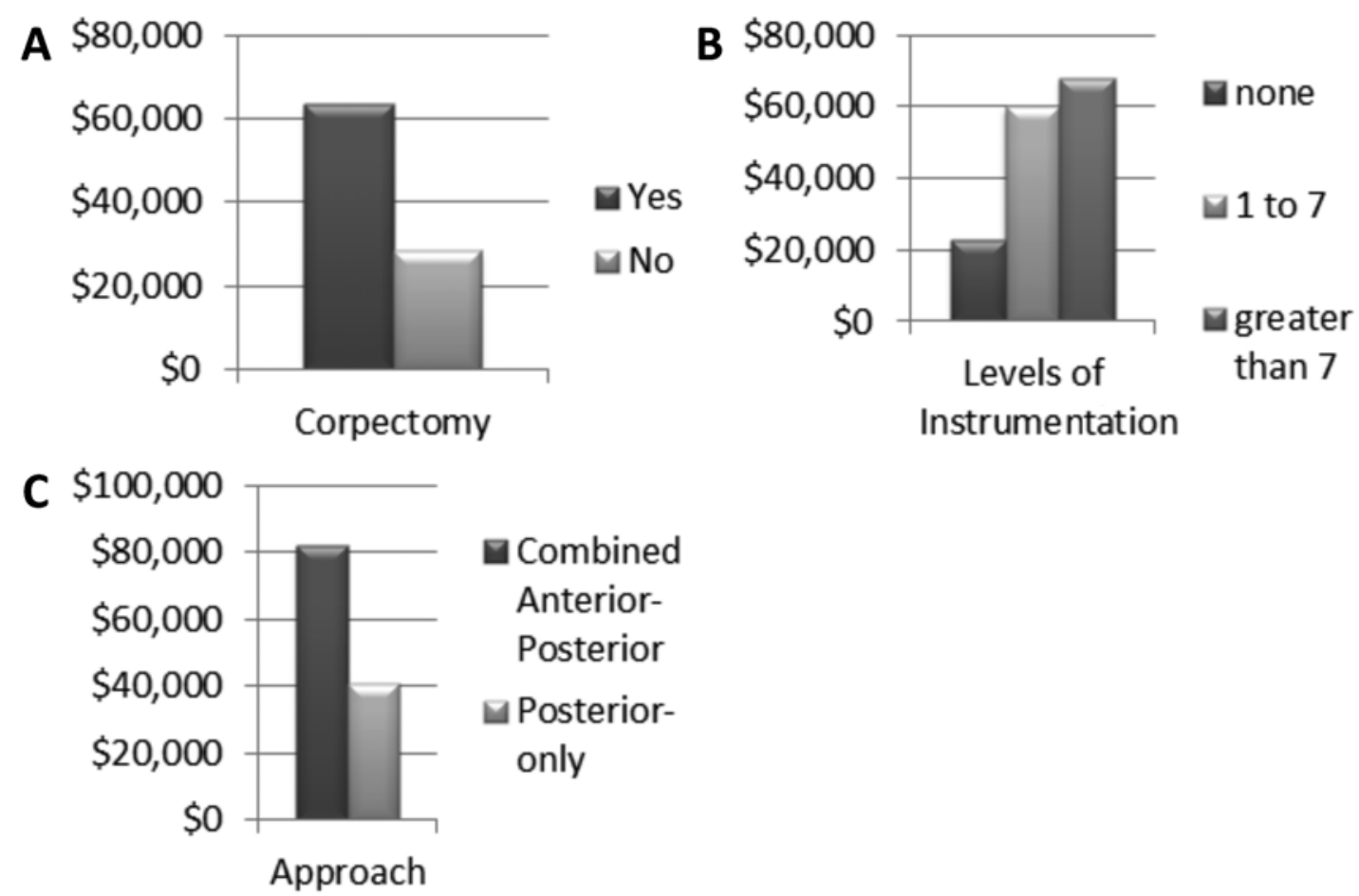

FIG. 2. Surgery-related factors significantly associated with hospital cost in patients undergoing surgery for spinal tumors.

Undergoing corpectomy $(p=0.021)(A)$, greater than 7 levels of instrumentation $(p<0.001)(B)$, and a combined anterior-posterior approach $(\mathrm{p}<0.001)(\mathbf{C})$ were independently associated with higher cost. 

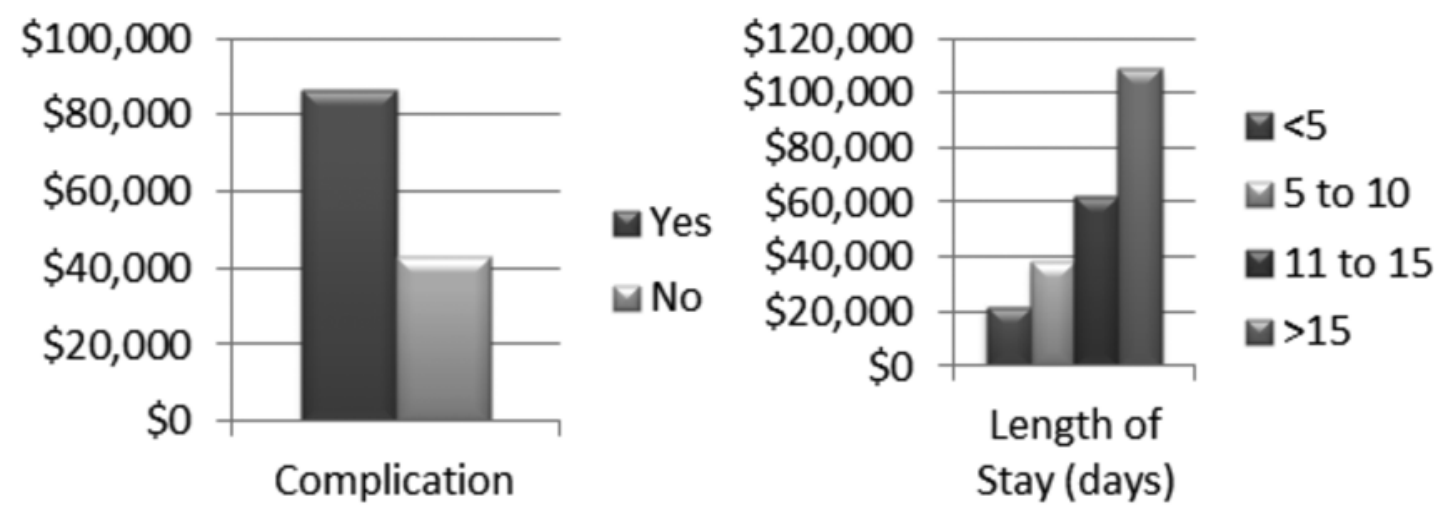

FIG. 3. Postoperative factors significantly associated with hospital cost in patients undergoing surgery for spinal tumors. Complication $(p<0.001)$ (left) and length of overall hospital stay greater than 15 days $(p<0.001)$ (right) were independently associated with higher cost.

Therefore, the extrapolation of the actual cost of surgery among these studies is difficult and limited. The cost is as high as $\$ 90,000$ in studies that stratify the cost of inpatient surgery for pathological bony fractures, ${ }^{17}$ and the cost of inpatient surgical treatment of spinal cord compression from spinal metastasis ranges from $\$ 43,691$ to $\$ 59,854 .{ }^{8}$ This is similar to the present study, for which the treatment of spinal metastasis was $\$ 50,098$.

In more homogeneous cohorts of patients who were surgically treated for spinal metastasis, the associated direct cost can be better evaluated. Chew et al. performed a prospective analysis of the cost associated with percutaneous vertebroplasty for the treatment of spinal metastasis in 11 patients. ${ }^{12}$ The overall cost (including consumables, capital equipment, hotel, clinic, and staffing costs) per patient was £2213. With a US dollar conversion rate of 1.5 times, this cost would be equivalent to $\$ 3319$. Relative to the cost of surgical management, vertebroplasty is extremely low cost and seemingly sustainable. However, the indications for vertebroplasty differ from those for the surgical management of spinal tumors, and thus the costs are not comparable. In a European prospective study by Turner et al., 74 patients with symptomatic spinal metastasis were enrolled in a study to evaluate the hospital cost of surgery. ${ }^{41}$ Among those patients, the average cost was $£ 16,885$ (equivalent to $\$ 25,327$ ); this is half the cost of what was observed in our cohort. Still, it remains difficult to compare the present study with the study by Turner et al. because of the intrinsic differences in the health care expenditure and reimbursement policies between the US and Europe. However, understanding and identifying differences between each health care system may aid in the identification of the key factors that influence spinal tumor surgery cost effectiveness.

In this study, the mean cost of surgery for primary spinal tumors was $\$ 52,083$. The cost reported in our study is lower than that reported by prior studies, with costs ranging from $\$ 61,157$ to $\$ 250,160 .{ }^{9,34}$ Sharma et al. performed a retrospective review of hospitalization cost on 15,545 admissions for spinal cord tumor surgery included in the US Nationwide Inpatient Sample database. ${ }^{34}$ Overall, between 2003 and 2007, the average cost of surgery was \$61,157. Interestingly, the cost in $2003(\$ 45,452)$ was significantly lower than in 2007 (\$76,698). These costs differ from those of extradural primary bony spinal tumor (chordoma and osteosarcoma) surgery. Brown et al. reported a mean total hospital cost ranging from $\$ 161,028$ to $\$ 250,160$ for 25 patients with sacral tumors who underwent sacrectomy. ${ }^{9}$ The cost of operating on sacral tumors in our study was much lower at $\$ 65,581$, though only a few patients underwent sacrectomy. There is an ongoing need for studies to evaluate the hospital cost associated with primary tumors of the cervical, thoracic, and lumbar spine.

It is clear that the costs of surgery for spinal tumors range widely and depend on a variety of factors. Identifying the factors that are modifiable is critical for decreasing the cost of spinal tumor surgery. Preoperative baseline clinical variables and tumor characteristics are factors that are typically not amendable to modification. In this study, male sex was independently associated with higher cost (an additional \$9752 or 1.2 times). A similar finding was also seen in a separate study on the surgical management of spinal metastasis. ${ }^{41}$ It is unclear why male sex is associated with a higher hospital cost, but it has been suggested that sex-specific cancers command different costs. Other identified factors independently associated with higher cost were the inability to ambulate (an additional $\$ 19,168$ or 1.4 times) and greater than 3 comorbidities (an additional $\$ 16,899-\$ 17,381$ or 1.3 times). It is evident that functional status and overall healthiness are variables that influence hospital-related costs. However, there are conflicting data about the relationship between patient comorbidity and hospital cost. Similar to our study, Sharma et al. demonstrated that patients with more comorbidities tend to accumulate higher hospital charges when undergoing surgery for spinal metastasis. ${ }^{34}$ The rationale is that patients with more medical issues tend to require additional medical care, procedures, and specialty consultations. On the other hand, Turner et al. showed that the EQ-5D and American Society of Anesthesia scores were inversely associated with cost for patients who underwent surgery for spinal cord tumors (i.e., sicker patients had lower hospital cost). ${ }^{41}$ In addition, their study showed that the Frankel grade was inversely associated with cost as well. Their explanation of their findings was that healthier and more functional patients underwent more aggressive 
TABLE 3. Analysis of the factors associated with the readmission rate of patients who underwent surgery for spinal tumors

\begin{tabular}{|c|c|c|c|}
\hline Variable & $\begin{array}{c}\text { No. of } \\
\text { Patients } \\
(\%)\end{array}$ & $\begin{array}{c}\text { No. } \\
\text { Readmitted } \\
(\%)\end{array}$ & $\begin{array}{c}p \\
\text { value }\end{array}$ \\
\hline Total & 181 & $21(11.6)$ & NA \\
\hline Tumor type & & & 0.880 \\
\hline Primary tumor & $63(34.8)$ & $7(11.1)$ & \\
\hline Met & $118(65.2)$ & $14(11.9)$ & \\
\hline Diagnosis & & & 0.100 \\
\hline Chordoma & $23(12.7)$ & $3(13.0)$ & \\
\hline Chondrosarcoma & $10(5.5)$ & $2(20.0)$ & \\
\hline Meningioma/nerve sheath tumor & $31(17.1)$ & $2(6.5)$ & \\
\hline Prostate met & $13(7.2)$ & $0(0.0)$ & \\
\hline Breast met & 20 (11.1) & $1(5.0)$ & \\
\hline Lung met & $21(11.6)$ & $5(23.8)$ & \\
\hline Renal cell met & $14(7.7)$ & $3(21.4)$ & \\
\hline Gastrointestinal met & $15(8.3)$ & $1(6.7)$ & \\
\hline Testicular met & $5(2.8)$ & $2(40.0)$ & \\
\hline Leiomyosarcoma met & $5(2.8)$ & $2(40.0)$ & \\
\hline Multiple myeloma/leukemia met & $6(3.3)$ & $0(0.0)$ & \\
\hline Melanoma met & $5(2.8)$ & $0(0.0)$ & \\
\hline Uterine/cervical met & $5(2.8)$ & $0(0.0)$ & \\
\hline Other & $8(4.4)$ & $0(0.0)$ & \\
\hline Age, yrs & & & 0.936 \\
\hline$<45$ & $39(21.5)$ & $4(10.3)$ & \\
\hline $45-65$ & $104(57.5)$ & $12(11.5)$ & \\
\hline$>65$ & $38(21.0)$ & $5(13.2)$ & \\
\hline Sex & & & 0.635 \\
\hline Male & $86(47.5)$ & $10(11.6)$ & \\
\hline Female & 95 (52.5) & $11(11.6)$ & \\
\hline Neurological deficit & & & 0.623 \\
\hline Yes & $103(56.9)$ & $13(12.6)$ & \\
\hline No & 78 (43.1) & $8(10.3)$ & \\
\hline Ambulatory & & & 0.531 \\
\hline Yes & 147 (81.2) & $16(10.9)$ & \\
\hline No & $34(18.8)$ & $5(14.7)$ & \\
\hline Radiation & & & 0.447 \\
\hline Yes & $40(22.1)$ & $6(15.0)$ & \\
\hline No & $141(77.9)$ & $15(10.6)$ & \\
\hline Extraspinal met & & & 0.422 \\
\hline 0 & $116(64.1)$ & $13(11.2)$ & \\
\hline 1 & $31(17.1)$ & $2(6.5)$ & \\
\hline 2 & $18(9.9)$ & $4(22.2)$ & \\
\hline$\geq 3$ & $16(8.8)$ & $2(12.5)$ & \\
\hline \multicolumn{4}{|l|}{ Comorbidities } \\
\hline Psychiatric & & & 0.525 \\
\hline Yes & $26(14.4)$ & $4(15.4)$ & \\
\hline No & 155 (85.6) & $17(11.0)$ & \\
\hline
\end{tabular}

CONTINUED IN NEXT COLUMN
》 CONTINUED FROM PREVIOUS COLUMN

TABLE 3. Analysis of the factors associated with the readmission rate of patients who underwent surgery for spinal tumors

\begin{tabular}{|c|c|c|c|}
\hline Variable & $\begin{array}{c}\text { No. of } \\
\text { Patients } \\
(\%)\end{array}$ & $\begin{array}{c}\text { No. } \\
\text { Readmitted } \\
(\%)\end{array}$ & $\begin{array}{c}p \\
\text { Value }\end{array}$ \\
\hline \multicolumn{4}{|c|}{ Comorbidities (continued) } \\
\hline Thyroid disease & & & 0.744 \\
\hline Yes & $14(7.7)$ & $2(14.3)$ & \\
\hline No & $167(92.3)$ & $19(11.4)$ & \\
\hline Pulmonary & & & 0.077 \\
\hline Yes & $21(11.6)$ & $0(0.0)$ & \\
\hline No & $160(88.4)$ & $21(13.1)$ & \\
\hline Vascular & & & 0.024 \\
\hline Yes & $18(9.9)$ & $5(27.8)$ & \\
\hline No & $163(90.1)$ & $16(9.8)$ & \\
\hline Hyperlipidemia & & & 0.695 \\
\hline Yes & $22(12.2)$ & $2(9.1)$ & \\
\hline No & $159(87.8)$ & $19(11.9)$ & \\
\hline Diabetes mellitus & & & 0.983 \\
\hline Yes & $17(9.4)$ & $2(11.8)$ & \\
\hline No & $164(90.6)$ & $19(11.6)$ & \\
\hline Liver disease & & & 0.239 \\
\hline Yes & $10(5.5)$ & $0(0.0)$ & \\
\hline No & $171(94.5)$ & $21(12.3)$ & \\
\hline Kidney disease & & & 0.871 \\
\hline Yes & $10(5.5)$ & $1(10.0)$ & \\
\hline No & $171(94.5)$ & $20(11.7)$ & \\
\hline Stroke & & & 0.088 \\
\hline Yes & $2(1.1)$ & $1(50.0)$ & \\
\hline No & $179(98.9)$ & $20(11.2)$ & \\
\hline Hypertension & & & 0.521 \\
\hline Yes & $54(29.8)$ & $5(9.3)$ & \\
\hline No & $127(70.2)$ & $16(12.6)$ & \\
\hline Heart disease & & & 0.547 \\
\hline Yes & $19(10.5)$ & $3(15.8)$ & \\
\hline No & $162(89.5)$ & 18 (11.1) & \\
\hline Total comorbidities & & & 0.472 \\
\hline None & $71(39.2)$ & $6(8.5)$ & \\
\hline $1-3$ & $98(54.1)$ & $14(14.3)$ & \\
\hline$>3$ & $12(6.6)$ & $1(8.3)$ & \\
\hline Spinal region & & & 0.083 \\
\hline Cervical & $34(18.8)$ & $0(0.0)$ & \\
\hline Thoracic & $85(47.0)$ & $11(12.9)$ & \\
\hline Lumbar & $43(23.8)$ & $8(18.6)$ & \\
\hline Sacral & $19(10.5)$ & $2(10.5)$ & \\
\hline Corpectomy & & & 0.057 \\
\hline Yes & $122(67.4)$ & $18(14.8)$ & \\
\hline No & $59(32.6)$ & $3(5.1)$ & \\
\hline
\end{tabular}


» CONTINUED FROM PAGE 373

TABLE 3. Analysis of the factors associated with the readmission rate of patients who underwent surgery for spinal tumors

\begin{tabular}{|c|c|c|c|}
\hline Variable & $\begin{array}{c}\text { No. of } \\
\text { Patients } \\
(\%)\end{array}$ & $\begin{array}{c}\text { No. } \\
\text { Readmitted } \\
(\%)\end{array}$ & $\begin{array}{c}p \\
\text { Value }\end{array}$ \\
\hline Fusion & & & 0.086 \\
\hline None & $54(29.8)$ & $3(5.6)$ & \\
\hline $1-7$ & $100(55.2)$ & $12(12.0)$ & \\
\hline$>7$ & $27(14.9)$ & $6(22.2)$ & \\
\hline Anterior-posterior approach & & & 0.227 \\
\hline Yes & $49(27.1)$ & $8(16.3)$ & \\
\hline No & $132(72.9)$ & $13(9.8)$ & \\
\hline Complication & & & 0.816 \\
\hline Yes & $38(21.0)$ & $4(10.5)$ & \\
\hline No & $143(79.0)$ & $17(11.9)$ & \\
\hline Length of stay, days & & & 0.184 \\
\hline$<5$ & $36(19.9)$ & $1(2.8)$ & \\
\hline $5-10$ & $75(41.4)$ & $9(12.0)$ & \\
\hline $11-15$ & $40(22.1)$ & $5(12.5)$ & \\
\hline$>15$ & $30(16.6)$ & $6(20.0)$ & \\
\hline
\end{tabular}

and complex surgeries. However, information on the specific surgical procedures performed is not available from a large national reimbursement-driven database, and their hypothesis cannot be confirmed.

The operative variables independently associated with higher hospital costs included surgeries that involved corpectomy (an additional $\$ 34,975$ or 2.2 times), instrumentation greater than 7 levels (an additional \$21,926-\$59,066 or 2.6-3.6 times), and utilizing a combined anterior-posterior approach ( $\$ 41,316$ or 2.0 times). These individual variables are likely surrogates and indicators for more complex cases that require a longer operative time, greater blood loss (thereby requiring blood transfusions), and longer hospital recovery, which are also factors that contribute to cost. With combined anterior-posterior approaches to the thoracic and lumbar spine, thoracic surgery and general surgery are often consulted for exposure, leading to additional costs. These findings demonstrate that the surgical management of spinal tumors that require large tumor resections and complex spinal reconstructions are associated with higher costs. Technically, these operative factors are modifiable, but the specific surgical procedure is dictated by the patient's clinical presentation, disease process, and goals. Understanding how to perform these complex cases in a safe and cost-efficient manner is key to lowering the overall associated hospital cost. For example, Brown et al. demonstrated that by staging complex tumor resections, specifically during sacrectomy, the cost decreased by a mean of $\$ 89,132$ per patient. ${ }^{9}$ In their study, the decreased costs were associated with decreases in length of stay in the intensive care unit, length of ventilator use, number of transfusions, and utilization of advanced pharmacy services.

The complications and length of stay have been robustly
TABLE 4. Results of the multivariate analysis of the factors that may influence the readmission rate of patients who undergo surgery for spinal tumors

\begin{tabular}{|c|c|c|c|}
\hline \multirow[b]{2}{*}{ Variable } & \multicolumn{3}{|c|}{ Readmission } \\
\hline & OR & $\mathrm{Cl}$ & $p$ Value \\
\hline \multicolumn{4}{|l|}{ Tumor type } \\
\hline Primary tumor & Ref & Ref & Ref \\
\hline Met & 1.09 & $<0.01$ to $>999.99$ & 0.999 \\
\hline \multicolumn{4}{|l|}{ Comorbidities } \\
\hline \multicolumn{4}{|l|}{ Pulmonary } \\
\hline Yes & $<0.01$ & $<0.01$ to $>999.99$ & 0.769 \\
\hline No & Ref & Ref & Ref \\
\hline \multicolumn{4}{|l|}{ Vascular } \\
\hline Yes & 4.27 & $0.53-34.48$ & 0.173 \\
\hline No & Ref & Ref & Ref \\
\hline \multicolumn{4}{|l|}{ Stroke } \\
\hline Yes & $>999.99$ & $<0.01$ to $>999.99$ & 0.881 \\
\hline No & Ref & Ref & Ref \\
\hline \multicolumn{4}{|l|}{ Diagnosis } \\
\hline Chordoma & 26.03 & $<0.01$ to $>999.99$ & 0.985 \\
\hline Chondrosarcoma & 4.14 & $<0.01$ to $>999.99$ & 0.993 \\
\hline $\begin{array}{l}\text { Meningioma/nerve } \\
\text { sheath tumor }\end{array}$ & 4.94 & $<0.01$ to $>999.99$ & 0.992 \\
\hline Prostate met & $<0.01$ & $<0.01$ to $>999.99$ & 0.892 \\
\hline Breast met & Ref & Ref & Ref \\
\hline Lung met & 52.99 & $2.96-948.39$ & 0.007 \\
\hline Renal cell met & 4.04 & $0.21-79.07$ & 0.358 \\
\hline Gastrointestinal met & 3.86 & $0.09-175.16$ & 0.488 \\
\hline Testicular met & 9.78 & $0.39-244.53$ & 0.165 \\
\hline Leiomyosarcoma met & 8.95 & $0.31-259.80$ & 0.202 \\
\hline $\begin{array}{l}\text { Multiple myeloma/ } \\
\text { leukemia met }\end{array}$ & $<0.01$ & $<0.01$ to $>999.99$ & 0.892 \\
\hline Melanoma met & 0.02 & $<0.01$ to $>999.99$ & 0.936 \\
\hline Uterine/cervical met & $<0.01$ & $<0.01$ to $>999.99$ & 0.916 \\
\hline Other & $<0.01$ & $<0.01$ to $>999.99$ & 0.897 \\
\hline \multicolumn{4}{|l|}{ Spinal region } \\
\hline Cervical & $<0.01$ & $<0.01$ to $>999.99$ & 0.564 \\
\hline Thoracic & 0.32 & 0.06 to 1.61 & 0.166 \\
\hline Lumbar & Ref & Ref & Ref \\
\hline Sacral & 0.07 & 0.01 to 1.51 & 0.090 \\
\hline \multicolumn{4}{|l|}{ Corpectomy } \\
\hline Yes & 5.20 & $0.60-45.24$ & 0.135 \\
\hline No & Ref & Ref & Ref \\
\hline \multicolumn{4}{|l|}{ Fusion } \\
\hline None & Ref & Ref & Ref \\
\hline $1-7$ & 0.44 & $0.05-3.90$ & 0.457 \\
\hline$>7$ & 1.60 & $1.17-15.48$ & 0.687 \\
\hline \multicolumn{4}{|l|}{ Length of stay, days } \\
\hline$<5$ & Ref & Ref & Ref \\
\hline $5-10$ & 5.43 & $0.67-43.81$ & 0.112 \\
\hline $11-15$ & 2.34 & $0.28-19.42$ & 0.432 \\
\hline$>15$ & 10.10 & $1.36-74.97$ & 0.024 \\
\hline
\end{tabular}




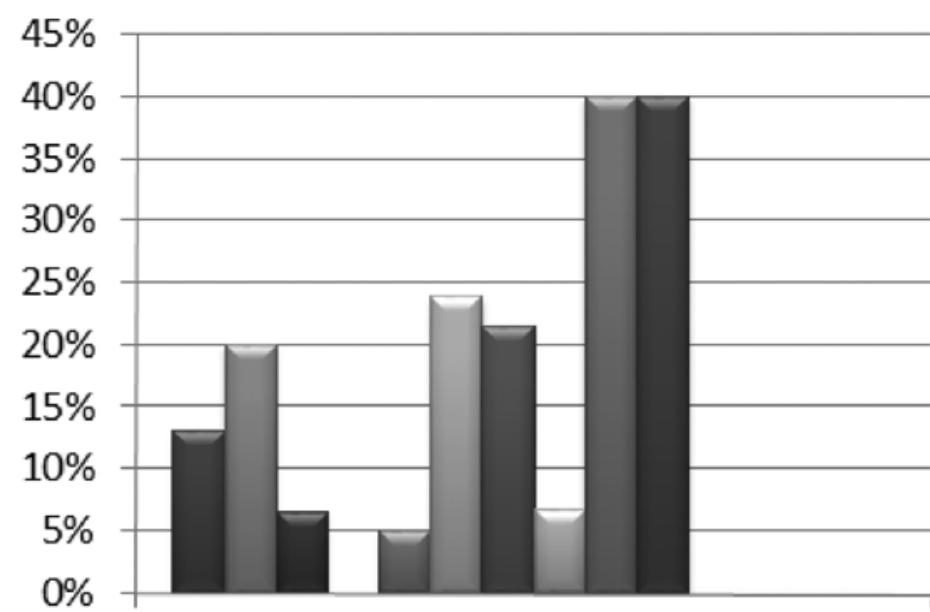

Pathological Diagnosis

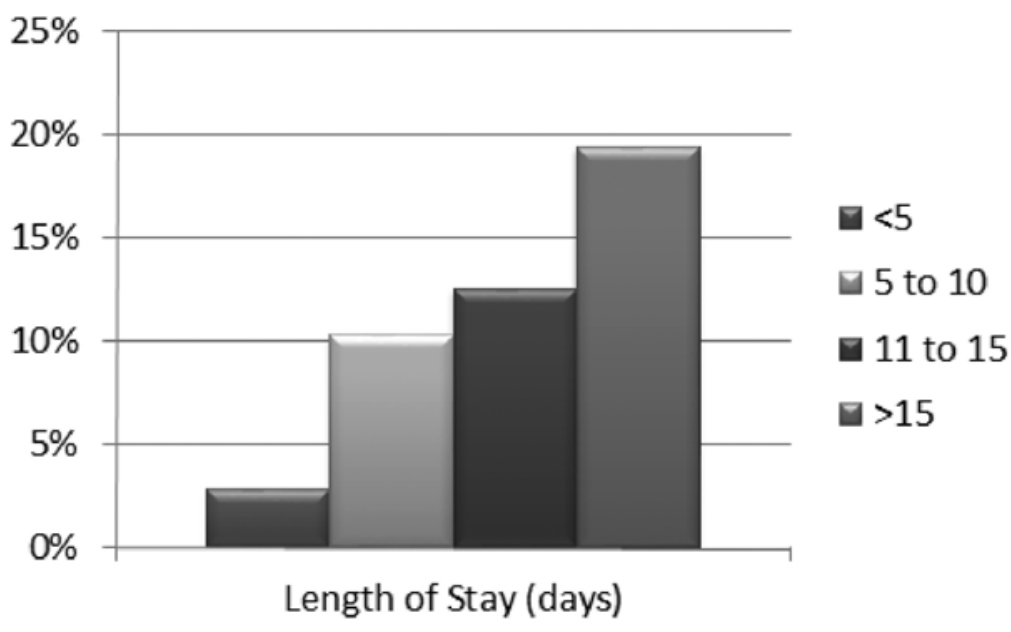

Chordoma

DChondrosarcoma

- Meningioma/Nerve Sheath Tumor

口 Prostate Met

Breast Met

$\square$ Lung Met

- Renal Cell Met

घastrointestinal Met

口Testicular Met

[Leiomyosarcoma Met

Multiple Myeloma/Leukem ia Met

$\checkmark$ Melanoma Met

$\square$ Uterine/Cervical Met

Gother

FIG. 4. Independent predictors of hospital readmission within 90 days of surgery for the resection of spinal tumor. Only the length of hospital stay greater than 15 days on index admission (lower) was independently associated with a higher odds of readmission (OR 6.62, $\mathrm{Cl}$ 1.30-33.74; $p=0.016)$. Met = metastasis.

shown to be associated with an increase in hospitalization cost across many subspecialties of medicine $e^{35,36,42}$ and in the surgical management of spinal tumors. ${ }^{34,41}$ Our study further supports these findings. Preventing complications and promoting faster postoperative recovery is paramount to decreasing the cost of hospitalization.

Another important consideration in evaluating the longer term cost effectiveness of surgery for spinal tumors is to understand the events that occur after discharge, particularly unforeseen readmission to the hospital. Hospital readmission is emerging as a quality indicator, and perhaps more importantly has a significant negative impact on patient satisfaction. ${ }^{40}$ The reported 90 -day readmission rate following various types of spine surgery (degenerative cervical spine to scoliosis deformity correction) ranges from $1.0 \%$ to $12.3 \% .^{4,5,32}$ The 90 -day readmission rate in our study falls into the higher range of the reported rates $(11.6 \%)$, with average hospital readmission costs totaling $\$ 20,078$. This cost is significant, especially when taking into account the number of patients who undergo spine tumor surgery. If approximately 1 in 10 patients are read- mitted with an average admission cost of approximately $\$ 20,000$, every 100 patients treated will result in an additional cost of $\$ 200,000$ from readmission. Therefore, understanding the risk factors for readmission is vital to preventing future readmission-associated costs. The most common reason for readmission was wound infection (57.1\% of the 21 readmissions), and of these infections $75.0 \%$ required surgical washout. Other authors have also reported that surgical site infections and wound complications were the most common reasons for readmission, making up to $46 \%$ to $72 \%$ of all readmissions during the 90-day discharge period..$^{5,32}$ In our study, the diagnosis of lung cancer and hospital stay longer than 15 days during the index hospitalization were independently associated with 90-day readmission, which is consistent with prior studies as well. ${ }^{6}$ Other previously identified risk factors for readmission following spine surgery include malignancy, longer operative time, longer constructs, higher patient severity of illness, and surgical complications. . $^{6,32}$ Over the 1-year postoperative period, the most common cause for readmission after spinal tumor surgery is tumor 
TABLE 5. Surgery-related causes for 90 -day readmission following spinal tumor surgery

\begin{tabular}{lc}
\hline \multicolumn{1}{c}{ Reason } & $\begin{array}{c}\text { No. of } \\
\text { Patients }\end{array}$ \\
\hline Primary tumors & \\
\hline Wound infection requiring surgical washout & 5 \\
\hline Wound infection not requiring reoperation & 2 \\
\hline Recurrent tumor requiring decompression & 1 \\
\hline Postoperative pain control & 1 \\
\hline Proximal junctional kyphosis requiring revision surgery & 1 \\
\hline Metastatic tumors & \\
\hline Wound infection not requiring washout & 4 \\
\hline Wound infection requiring washout & 1 \\
\hline Dyspnea due to pleural effusion & 2 \\
\hline Severe ileus & 1 \\
\hline Tumor progression w/ myelopathy requiring reoperation & 1 \\
\hline Deep vein thrombosis requiring anticoagulation & 1 \\
\hline Screw pullout \& cage subsidence requiring revision & 1 \\
\hline surgery & \\
\hline
\end{tabular}

recurrence (33\% of readmissions). ${ }^{33}$ Specifically, aggressive metastatic spinal tumors (lung, osteosarcoma, stomach, bladder, esophagus, and pancreas) and the presence of medical comorbidities increased the risk for readmission..$^{33}$

Attention to the negative findings from a study are also valuable in understanding the factors associated with direct cost. There are often various clinical and patient factors that would be expected to have an impact on direct hospital cost, but this really needs verification. Based on this study, it is surprising that pathological diagnosis, age, history of radiation therapy, and presence of extraspinal metastasis did not have significant associations with direct hospital cost. In addition, none of these factors, except pathological diagnosis, influenced the 90-day readmission rate. These findings may indicate that such outcomes are not dictated strictly on the presence of certain preoperative clinical demographics, but rather how these factors are managed medically and surgically.

Traditionally, it is understood that patients with metastatic cancers would be at greater risk of complications, higher cost, and more frequent readmissions. However, this study suggests the opposite: similar costs and readmission outcomes were observed between patients with metastatic and primary spinal tumors. These findings may be explained by careful patient selection among those with metastatic tumors. All patients with metastasis underwent comprehensive evaluation by an oncology team prior to surgery to determine disease burden and prognosis. Only patients with favorable life expectancy (greater than 3 months) were offered surgery. These patients most likely also had favorable Karnofsky Performance Scale scores and, thus, were able to tolerate resection well. On the contrary, if all patients with metastatic spinal tumors (regardless of cancer burden and health status) were offered surgery, worse outcome and higher associated cost may be observed.

Radiation has been understood to be a major risk fac- tor for wound breakdown, dehiscence, and poor healing. However, we did not observe significant differences in the hospital costs and 90-day readmission rates between patients who underwent radiation therapy and patients without radiation treatment. This may be explained by the evolution of how radiation is delivered to spinal tumors. Over the past several years, there has been a transition to the use of stereotactic radiosurgery via high-dose, hypofractionated, image-guided radiation therapy, rather than conventional fractional radiotherapy ${ }^{20} \mathrm{~A}$ recent published study by Harel et al. concluded that modern-day adjuvant stereotactic radiosurgery (single fraction) to the spine following surgery for metastasis allows high local control rates, but at the same time delivers less radiation to the wound.$^{18}$ Additional contemporary studies are needed to further evaluate this topic.

There are several limitations to the present study related to its single-center and retrospective design. Hospital cost is associated with a multitude of variables, many of which are not reliably accounted for with a retrospective study. This generates undetected confounders that were not adjusted for in the multivariate analysis. A prospective study that is designed to record all hospitalization costs and activities may aid in elucidating additional factors associated with surgical cost. As a single-center study, this investigation may lack generalizability of the present findings because costs typically vary by location, institution, and geography, which are composed of different local health care microclimates. Despite these limitations, the data provided in this study offer new insights into the cost associated with surgery for spinal tumors. Additional studies are needed to examine the long-term functional outcomes and assess the cost effectiveness of surgery for spinal tumors, such as that undertaken by Tipsmark et al., who analyzed the total health care cost of 629 patients who underwent spinal metastasis treatment from the initiation of treatment (i.e., index hospitalization) until death. ${ }^{37}$

\section{Conclusions}

The overall mean hospital cost associated with the surgical management of spinal tumors was $\$ 52,083$, and there is no difference in the mean cost between treating primary and metastatic spinal tumors. The factors affecting cost can be stratified based on nonmodifiable and modifiable factors. The identified independent risk factors for high cost include male sex, nonambulatory status, more than 3 comorbidities, corpectomy, more than 7 levels of instrumentation, combined anterior-posterior approach, presence of perioperative complications, and longer lengths of stay. Many of these factors are surrogates for worse disease that warrant more complex surgical interventions. The overall readmission rate was $11.6 \%$, which is similar to the readmission rates following complex spine surgery. Additional studies that look at long-term outcome and cost effectiveness should be undertaken, as they may add to the understanding of the costs associated with the surgical management of spinal tumors.

\section{References}

1. Adogwa O, Owens R, Karikari I, Agarwal V, Gottfried ON, 
Bagley CA, et al: Revision lumbar surgery in elderly patients with symptomatic pseudarthrosis, adjacent-segment disease, or same-level recurrent stenosis. Part 2. A cost-effectiveness analysis. Clinical article. J Neurosurg Spine 18:147-153, 2013

2. Adogwa O, Parker SL, Davis BJ, Aaronson O, Devin C, Cheng JS, et al: Cost-effectiveness of transforaminal lumbar interbody fusion for Grade I degenerative spondylolisthesis. J Neurosurg Spine 15:138-143, 2011

3. Adogwa O, Parker SL, Shau DN, Mendenhall SK, Devin CJ, Cheng JS, et al: Cost per quality-adjusted life year gained of laminectomy and extension of instrumented fusion for adjacent-segment disease: defining the value of surgical intervention. J Neurosurg Spine 16:141-146, 2012

4. Akamnonu C, Cheriyan T, Goldstein JA, Errico TJ, Bendo JA: Ninety-day readmissions after degenerative cervical spine surgery: A single-center administrative database study. Int J Spine Surg 9:19, 2015

5. Akamnonu C, Cheriyan T, Goldstein JA, Lafage V, Errico TJ, Bendo JA: Unplanned hospital readmission after surgical treatment of common lumbar pathologies: rates and causes. Spine (Phila Pa 1976) 40:423-428, 2015

6. Akins PT, Harris J, Alvarez JL, Chen Y, Paxton EW, Bernbeck J, et al: Risk factors associated with 30-day readmissions after instrumented spine surgery in 14,939 patients: 30-day readmissions after instrumented spine surgery. Spine (Phila Pa 1976) 40:1022-1032, 2015

7. Angevine PD, Zivin JG, McCormick PC: Cost-effectiveness of single-level anterior cervical discectomy and fusion for cervical spondylosis. Spine (Phila Pa 1976) 30:1989-1997, 2005

8. Barlev A, Song X, Ivanov B, Setty V, Chung K: Payer costs for inpatient treatment of pathologic fracture, surgery to bone, and spinal cord compression among patients with multiple myeloma or bone metastasis secondary to prostate or breast cancer. J Manag Care Pharm 16:693-702, 2010

9. Brown MJ, Kor DJ, Curry TB, Warner MA, Rodrigues ES, Rose SH, et al: Sacral tumor resection: the effect of surgical staging on patient outcomes, resource management, and hospital cost. Spine (Phila Pa 1976) 36:1570-1578, 2011

10. Carreon LY, Anderson PA, Traynelis VC, Mummaneni PV, Glassman SD: Cost-effectiveness of single-level anterior cervical discectomy and fusion five years after surgery. Spine (Phila Pa 1976) 38:471-475, 2013

11. Carreon LY, Glassman SD, Djurasovic M, Campbell MJ, Puno RM, Johnson JR, et al: RhBMP-2 versus iliac crest bone graft for lumbar spine fusion in patients over 60 years of age: a cost-utility study. Spine (Phila Pa 1976) 34:238243, 2009

12. Chew C, O'Dwyer PJ, Edwards R: Health service cost associated with percutaneous vertebroplasty in patients with spinal metastases. Clin Radiol 68:776-779, 2013

13. Decroisette C, Monnet I, Berard H, Quere G, Le Caer H, Bota S, et al: Epidemiology and treatment costs of bone metastases from lung cancer: a French prospective, observational, multicenter study (GFPC 0601). J Thorac Oncol 6:576-582, 2011

14. Delea T, Langer C, McKiernan J, Liss M, Edelsberg J, Brandman J, et al: The cost of treatment of skeletal-related events in patients with bone metastases from lung cancer. Oncology 67:390-396, 2004

15. Fehlings MG, Nater A, Holmer H: Cost-effectiveness of surgery in the management of metastatic epidural spinal cord compression: a systematic review. Spine (Phila Pa 1976) 39 (22 Suppl 1):S99-S105, 2014

16. Glassman SD, Polly DW, Dimar JR, Carreon LY: The cost effectiveness of single-level instrumented posterolateral lumbar fusion at 5 years after surgery. Spine (Phila Pa 1976) 37:769-774, 2012
17. Hagiwara M, Delea TE, Saville MW, Chung K: Healthcare utilization and costs associated with skeletal-related events in prostate cancer patients with bone metastases. Prostate Cancer Prostatic Dis 16:23-27, 2013

18. Harel R, Emch T, Chao S, Elson P, Krishnaney A, Djemil $\mathrm{T}$, et al: Quantitative evaluation of local control and wound healing following surgery and stereotactic spine radiosurgery (SRS) for spine tumors. World Neurosurg [epub ahead of print], 2015

19. Kaloostian PE, Zadnik PL, Etame AB, Vrionis FD, Gokaslan ZL, Sciubba DM: Surgical management of primary and metastatic spinal tumors. Cancer Contr 21:133-139, 2014

20. Keam J, Bilsky MH, Laufer I, Shi W, Zhang Z, Tam M, et al: No association between excessive wound complications and preoperative high-dose, hypofractionated, image-guided radiation therapy for spine metastasis. J Neurosurg Spine 20:411-420, 2014

21. Kuntz KM, Snider RK, Weinstein JN, Pope MH, Katz JN: Cost-effectiveness of fusion with and without instrumentation for patients with degenerative spondylolisthesis and spinal stenosis. Spine (Phila Pa 1976) 25:1132-1139, 2000

22. Lage MJ, Barber BL, Harrison DJ, Jun S: The cost of treating skeletal-related events in patients with prostate cancer. Am J Manag Care 14:317-322, 2008

23. Lau D, Leach MR, La Marca F, Park P: Independent predictors of survival and the impact of repeat surgery in patients undergoing surgical treatment of spinal metastasis. J Neurosurg Spine 17:565-576, 2012

24. McCarthy I, Hostin R, O'Brien M, Saigal R, Ames CP: Health economic analysis of adult deformity surgery. Neurosurg Clin N Am 24:293-304, 2013

25. McCarthy I, O’Brien M, Ames C, Robinson C, Errico T, Polly DW Jr, et al: Incremental cost-effectiveness of adult spinal deformity surgery: observed quality-adjusted life years with surgery compared with predicted quality-adjusted life years without surgery. Neurosurg Focus 36(5):E3, 2014

26. McCarthy IM, Hostin RA, Ames CP, Kim HJ, Smith JS, Boachie-Adjei O, et al: Total hospital costs of surgical treatment for adult spinal deformity: an extended follow-up study. Spine J 14:2326-2333, 2014

27. Meyer SA, Mummaneni PV: Cost-effectiveness of transforaminal lumbar interbody fusion. J Neurosurg Spine 15:136-137, 2011

28. Munoz-Bendix C, Slotty PJ, Ahmadi SA, Bostelmann R, Steiger HJ, Cornelius JF: Primary bone tumors of the spine revisited: A 10-year single-center experience of the management and outcome in a neurosurgical department. J Craniovertebr Junction Spine 6:21-29, 2015

29. Ortiz Gómez JA: The incidence of vertebral body metastases. Int Orthop 19:309-311, 1995

30. Parker SL, Adogwa O, Bydon A, Cheng J, McGirt MJ: Costeffectiveness of minimally invasive versus open transforaminal lumbar interbody fusion for degenerative spondylolisthesis associated low-back and leg pain over two years. World Neurosurg 78:178-184, 2012

31. Parker SL, Fulchiero EC, Davis BJ, Adogwa O, Aaronson OS, Cheng JS, et al: Cost-effectiveness of multilevel hemilaminectomy for lumbar stenosis-associated radiculopathy. Spine J 11:705-711, 2011

32. Schairer WW, Carrer A, Deviren V, Hu SS, Takemoto S, Mummaneni P, et al: Hospital readmission after spine fusion for adult spinal deformity. Spine (Phila Pa 1976) 38:16811689,2013

33. Schairer WW, Carrer A, Sing DC, Chou D, Mummaneni PV, $\mathrm{Hu}$ SS, et al: Hospital readmission rates after surgical treatment of primary and metastatic tumors of the spine. Spine (Phila Pa 1976) 39:1801-1808, 2014

34. Sharma M, Sonig A, Ambekar S, Nanda A: Discharge dispositions, complications, and costs of hospitalization in spinal 
cord tumor surgery: analysis of data from the United States Nationwide Inpatient Sample, 2003-2010. J Neurosurg Spine 20:125-141, 2014

35. Starks H, Wang S, Farber S, Owens DA, Curtis JR: Cost savings vary by length of stay for inpatients receiving palliative care consultation services. J Palliat Med 16:1215-1220, 2013

36. Stephen AE, Berger DL: Shortened length of stay and hospital cost reduction with implementation of an accelerated clinical care pathway after elective colon resection. Surgery 133:277-282, 2003

37. Tipsmark LS, Bünger CE, Wang M, Morgen SS, Dahl B, Søgaard R: Healthcare costs attributable to the treatment of patients with spinal metastases: a cohort study with up to 8 years follow-up. BMC Cancer 15:354, 2015

38. Tosteson AN, Lurie JD, Tosteson TD, Skinner JS, Herkowitz $\mathrm{H}$, Albert T, et al: Surgical treatment of spinal stenosis with and without degenerative spondylolisthesis: cost-effectiveness after 2 years. Ann Intern Med 149:845-853, 2008

39. Tosteson AN, Skinner JS, Tosteson TD, Lurie JD, Andersson GB, Berven S, et al: The cost effectiveness of surgical versus nonoperative treatment for lumbar disc herniation over two years: evidence from the Spine Patient Outcomes Research Trial (SPORT). Spine (Phila Pa 1976) 33:2108-2115, 2008

40. Tsai TC, Joynt KE, Orav EJ, Gawande AA, Jha AK: Variation in surgical-readmission rates and quality of hospital care. N Engl J Med 369:1134-1142, 2013

41. Turner I, Minhas Z, Kennedy J, Morris S, Crockard A, Choi D: Cost of surgery for symptomatic spinal metastases in the UK. World Neurosurg 84:1235-1243, 2015

42. Vonlanthen R, Slankamenac K, Breitenstein S, Puhan MA, Muller MK, Hahnloser D, et al: The impact of complications on costs of major surgical procedures: a cost analysis of 1200 patients. Ann Surg 254:907-913, 2011

43. Whitmore RG, Schwartz JS, Simmons S, Stein SC, Ghogawala Z: Performing a cost analysis in spine outcomes research: comparing ventral and dorsal approaches for cervical spondylotic myelopathy. Neurosurgery 70:860-867, 2012
44. Zong S, Zeng G, Xiong C, Wei B: Treatment results in the differential surgery of intradural extramedullary schwannoma of 110 cases. PLoS One 8:e63867, 2013

\section{Disclosures}

The authors report the following. Dr. Ames is an employee of UCSF, is a consultant for DePuy, Stryker, and Medtronic, owns stock in Doctors Research Group, holds patents with Fish \& Richardson, P.C., and receives royalties from Stryker and Biomet Spine. Dr. Berven owns stock in Simpirica and Providence Medical and is a consultant for Medtronic, Globus, Stryker, and RTI. Dr. Burch is a consultant for Medtronic, receives clinical or research support for the study described from Lily, Inc., and Integra Life Sciences, and receives spine fellowship support from AOSpine, Globus, and NuVasive. Dr. Chou is a consultant for Globus, Medtronic, and Orthofix. Dr. Deviren is a consultant for NuVasive, Guidepoint, and Stryker and receives spine fellowship support from NuVasive, Globus, and AOSpine. Dr. Mummaneni is a consultant for Stryker, owns stock in Spinicity/ISD, owns royalties with DePuy Spine, Taylor and Francis Publishing, Springer Publishing, and Thieme Publishing, receives honoraria from Globus, and receives non-study-related clinical or research support from AOSpine and NREF.

\section{Author Contributions}

Conception and design: Ames, Lau. Acquisition of data: Lau, Chan. Analysis and interpretation of data: Lau. Drafting the article: Ames, Lau, Chan. Critically revising the article: all authors. Reviewed submitted version of manuscript: all authors. Approved the final version of the manuscript on behalf of all authors: Ames. Statistical analysis: Lau. Study supervision: Ames.

\section{Correspondence}

Christopher P. Ames, Department of Neurological Surgery, University of California, San Francisco, 400 Parnassus Ave., A850, San Francisco, CA 94143. email: amesc@neurosurg.ucsf.edu. 